\title{
Pesticides handling practices among potato growers in Kavrepalanchok, Nepal
}

\author{
${ }^{1}$ Kashi Ram Sapkota*, ${ }^{2}$ Sundar Sapkota, ${ }^{3}$ Sanjib Sapkota and ${ }^{4}$ Krishna Katuwal \\ ${ }^{1}$ Department of Agriculture, Agriculture and Forestry University, Rampur, Nepal \\ ${ }^{2}$ Department of Biology, Eastern New Mexico University, Portales, NM 88130, USA \\ ${ }^{3}$ Department of Biological Sciences, Simon Fraser University, Burnaby, V5A 1S6, Canada \\ ${ }^{4}$ Department of Crop and Soil Sciences, University of Georgia, Athens, GA 30602, USA \\ *Correspondence: sapkotakashi290@ gmail.com; ORCID: https://orcid.org/0000-0001-6310-2344 \\ Received: September 12, 2019; Accepted: December 15, 2019; Published: January 7, 2020 \\ (C) Copyright: Sapkota et al. (2020). \\ (c) (1) (3) \\ International License.
}

\begin{abstract}
The rate of pesticide application in the agricultural field is surging. Farmers are getting exposed to pesticide hazards from the misuse and unsafe handling of pesticides. The study was conducted among 101 potato growers in Kaverpalanchok district of Nepal in 2018. The objective of the study was to assess the knowledge, status, and pesticide handling practices among potato growers. Around 94\% farmers applied pesticides against early and late blight. Only 5\% growers treated seed before potato sowing. About 93 and $73 \%$ farmers sprayed pesticides 2-10 times/season into the field and spent 2-6 hours/pesticide spray respectively. More than $2 / 3^{\text {rd }}$ growers did not read the pesticide labels, and nearly $95 \%$ growers received information on pesticide applications from agrovet rather than authorized government bodies. Only 13\% farmers had received Integrated Pest Management (IPM) training. However, $1 / 4^{\text {th }}$ of them had practiced IPM techniques. The majority of the growers used masks, rubber boots, and long-sleeved clothes during pesticide handling. Nearly $2 / 3^{\text {rd }}$ growers threw pesticide containers anywhere in the environment. Concerned authorities should provide IPM training, skill-building programs on pesticide handling and awareness on waiting period and environmental hazards to avoid pesticide risk.
\end{abstract}

Keywords: Environment, Farmers, Health, IPM, Pesticides

Correct citation: Sapkota, K. R, Sapkota, S, Sapkota, S, \& Katuwal, K. (2020). Pesticides handling practices among potato growers in Kavrepalanchok, Nepal. Journal of Agriculture and Natural Resources, 3(1), 77-87. DOI: https://doi.org/10.3126/janr.v3i1.27093 
Journal of Agriculture and Natural Resources (2020) 3(1): 77-87

ISSN: 2661-6270 (Print), ISSN: 2661-6289 (Online)

DOI: https://doi.org/10.3126/janr.v3i1.27093

\section{INTRODUCTION}

Pesticides are toxic chemicals used to kill pests (insects, weeds) and plant diseases, which have a long-term impact on the environment and human life (Pimental, 2005; Sharma et al., 2012). Pesticides misuse is a serious concern in commercial agriculture. Pesticide spraying in an unsafe manner creates acute and chronic health problems. Health problems such as cancer, skin irritation and respiratory diseases are increasing because of incidental and occupational exposure to the pesticides (Konradsen et al., 2003). Globally, around 2 million tons of pesticides are sprayed each year in agricultural land (Sharma et al., 2012; Dhital et al., 2015). A majority (45\%) of the pesticides are consumed in Europe followed by the USA (24\%). Pesticides use in Nepal is very low (0.142 a.i. kg/ha) compared to UK (5), USA (7), Netherlands (9.4), Japan (12), China (14) and Taiwan (17) (Sharma et al., 2012; Dhital et al., 2015). The use of pesticides in Nepal started with DDT in the early 1950s to eradicate malaria. Different categories of pesticides such as Organochlorines (BHC, Dieldrin), organophosphate (Ethyl parathion, Malathion), carbamates and synthetic pyrethroids were entered in Nepal after 1950s (Atreya, 2008; Shrestha et al., 2010; Kafle et al., 2015).

In Nepal, five hundred different pesticide brands are available (Khanal and Singh, 2016). Farmers are using pesticides to control insects such as brown planthopper and fruit flies. In addition, chemical pesticides have been used to control plant diseases such as late blight of potato and tomato (Atreya, 2008). The pesticide application rate is rising by $10-20 \%$ per year (Khanal and Singh, 2016). However, a greater proportion of farmers are unaware of pesticide types, poison level, safety precautions, and pesticide effects on health and environment (Yassin et al., 2002).

Earlier studies have reported Nepalese potato farmers are using several types of pesticides such as organophosphates, pyrethroids and organochlorines. Notably, Endosulfan, Malathion and Mancozeb are still very common among potato farmers of Nepal (Giri et al., 2009). Sharma et al. (2012) reported that pesticide used in potato was very low in Nepal during 1980 's. Less than one percent of potato farmers used to spray pesticides during that period. However, a study conducted by Atreya (2005) in central mid-hills of Nepal showed farmers were extensively applying pesticides on potato crops for more than a decade.

Despite the higher use of pesticides, research reports are inconclusive about pesticide handling practices in Panchkhal and Banepa municipalities of Kavrepalanchowk district. Thus, this study aimed to assess knowledge, status, and pesticide handling practices among potato growers in Kavrepalanchok district, Nepal.

\section{METHODOLOGY}

\section{Study Site}

A household survey was conducted in Kavrepalanchok district of Nepal in 2018. The study site is situated at longitude: $85^{\circ} 33^{\prime} 40.32^{\prime \prime} \mathrm{E}$, latitude: $27^{\circ} 31^{\prime} 33.24^{\prime \prime} \mathrm{N}$ and an elevation: 280 3018. Two municipalities, Panchkhal and Banepa were selected purposively as these areas were noted for maximum use of pesticides. Banepa $\left(27.6332^{\circ} \mathrm{N}, 85.5277^{\circ} \mathrm{E}\right)$ is a mid-hilly region located approximately $25 \mathrm{~km}$ east of the capital city of Nepal, Kathmandu. The area experiences a subtropical climate. Moreover, Panchkhal $\left(27.6564^{\circ} \mathrm{N}, 85.6126^{\circ} \mathrm{E}\right)$ is a valley 
Journal of Agriculture and Natural Resources (2020) 3(1): 77-87

ISSN: 2661-6270 (Print), ISSN: 2661-6289 (Online)

DOI: https://doi.org/10.3126/janr.v3i1.27093

located approximately $47 \mathrm{~km}$ east of the capital city of Nepal, Kathmandu and experiences subtropical climate.

\section{Selection of respondents}

The total sampling population size was 1,010 . The information about population size was obtained from Potato Super Zone, Kavrepalanchok. From sampling population, 101 respondents were randomly selected. For that, we selected 50 farmers from Banepa (25 each from Shumara and Chunatal), and 51 farmers from Panchkhal (13 each from Shrirampati, Rampur, and Anekot; 6 each from Pipaltar and Tamaghat) municipaliity.

\section{Data collection and analysis}

Primary data were collected from potato growers through personal interviews using questionnaire. The data were analyzed using MS-Excel 2016 and SPSS 2009 (SPSS, 2009).

\section{RESULTS AND DISCUSSION}

\section{Socio-demographic characteristics}

The data analysis indicated that there were $56.4 \%$ males and $43.6 \%$ females involved in potato farming (Fig. 1). The potato farmers had an average age of 37.31 years with average years of schooling of 6.89. The average family size of the respondents was about 5 members per family. The respondents had cultivated potato in a medium scale (0.445 ha) (Table 1$)$.

Table 1. Socio-demographic characteristics of the respondents in Panchkhal and Banepa, Kavrepalanchowk ( $\mathbf{N}=101)$.

\begin{tabular}{lccc}
\hline Parameters & Mean & SD & SE \\
\hline Age (years) & 37.31 & 11.54 & 1.149 \\
Education (schooling years) & 6.89 & 4.67 & 0.464 \\
Family size (number) & 5.435 & 2.325 & 0.040 \\
Potato cultivated land (ha) & 0.445 & 0.305 & 0.0304 \\
\hline
\end{tabular}

Source: Field Survey, 2018

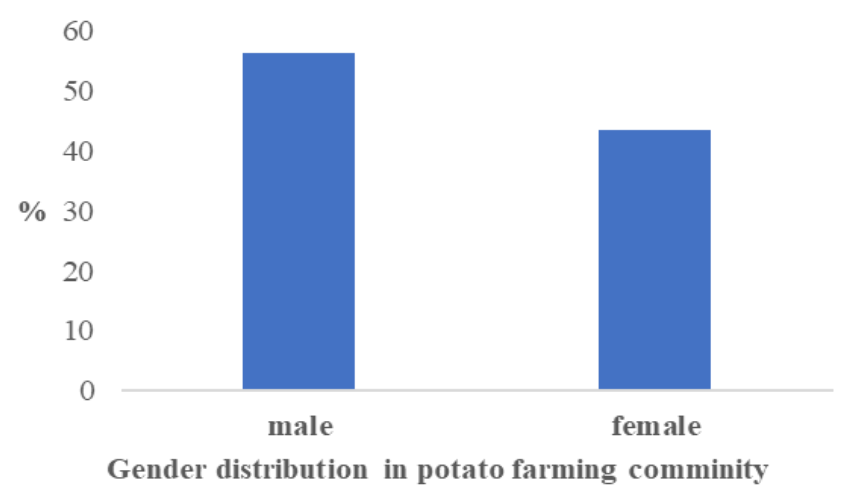

Fig. 1. Gender distribution in potato farming community in Panchkhal and Banepa, Kavrepalanchowk 
Journal of Agriculture and Natural Resources (2020) 3(1): 77-87

ISSN: 2661-6270 (Print), ISSN: 2661-6289 (Online)

DOI: https://doi.org/10.3126/janr.v3i1.27093

\section{Pesticides handling practices}

Pesticides handling practices in Kavrepalanchok is shown in Table 2. Majority (57.4\%) of the pesticide applicators were males. Nearly $61 \%$ of the farmers used power sprayer, whereas $39 \%$ used Knapsack sprayer. The probable reason could be associated with easy handling, low cost, and high efficiency of the power sprayer. Almost $94 \%$ of the farmers sprayed pesticides against early and late blight diseases, and only $6 \%$ respondents applied pesticides against insects and weeds. This infers that the fungal infestations are higher compared to other pests in the potato field. More than half of the farmers had applied pesticides before disease and pest infestation. Almost 38\% of the farmers had applied pesticides after pest appeared in the field. Nearly $11 \%$ of the farmers sprayed pesticides after pests damage their crops. A study conducted by Rijal et al. (2018) in Chitwan district reported that about 54\% of the farmers sprayed pesticides right after the appearance of pests. Two-fifths of the potato growers did not account for windy days for pesticide spraying. Wind may divert pesticides from targeted crops leading to pesticide wastage as well as human health problems. Khanal and Singh (2016) reported 90\% farmers in Chitwan district considered wind direction during pesticide application. In the study area, a total of $95 \%$ farmers had not treated seed before potato sowing. Almost three-fifths of the potato growers had not applied any chemicals during potato seed storage at home. Nearly 21, 12, and 5\% farmers used Malathion, Novan and Metacid respectively to control Potato Tuber Moth (PTM) during potato seed storage.

Table 2. Pesticide handling practices in Panchkhal and Banepa, Kavrepalanchowk (N =101).

\begin{tabular}{|c|c|c|}
\hline Parameters & Frequency & Percent \\
\hline \multicolumn{3}{|l|}{ Pesticide applicator } \\
\hline Male & 58 & 57.4 \\
\hline Female & 43 & 42.6 \\
\hline \multicolumn{3}{|l|}{ Equipment used for spraying } \\
\hline Power sprayer & 62 & 61.4 \\
\hline Knapsack sprayer & 39 & 38.6 \\
\hline \multicolumn{3}{|l|}{ Pesticide used against } \\
\hline Insects and weeds & 6 & 5.9 \\
\hline Early and late blight (fungus) & 95 & 94.1 \\
\hline \multicolumn{3}{|l|}{ Situation of pesticide use } \\
\hline $\begin{array}{l}\text { Before infestation of disease and appearance of } \\
\text { pests }\end{array}$ & 52 & 51.5 \\
\hline After appearance of pests & 38 & 37.6 \\
\hline After damage seen in crops & 11 & 10.9 \\
\hline \multicolumn{3}{|l|}{ Pesticide application during windy days } \\
\hline Yes & 40 & 39.6 \\
\hline No & 61 & 60.4 \\
\hline \multicolumn{3}{|l|}{ Seed treatment before potato sowing } \\
\hline No & 96 & 95 \\
\hline Yes & 5 & 5 \\
\hline \multicolumn{3}{|l|}{$\begin{array}{l}\text { Pesticide used during potato seed storage at } \\
\text { home }\end{array}$} \\
\hline No chemical used & 63 & 62.4 \\
\hline Malathion powder (For PTM) & 21 & 20.8 \\
\hline Novan (For PTM) & 12 & 11.9 \\
\hline Metacid (For PTM) & 5 & 5 \\
\hline
\end{tabular}

Source: Field Survey, 2018, PTM = Potato Tuber Moth

More than half of the farmers stored pesticides in a storeroom whereas only $4 \%$ used kitchen to store pesticides (Fig. 2). A similar report was mentioned by Shrestha et al. (2010) that 
Journal of Agriculture and Natural Resources (2020) 3(1): 77-87

ISSN: 2661-6270 (Print), ISSN: 2661-6289 (Online)

DOI: https://doi.org/10.3126/janr.v3i1.27093

majority of the farmers store pesticide in a storeroom in the Dhading district. Farmers should store chemical pesticides in a safe place to avoid adverse consequences. About $73 \%$ of potato farmers had spent 2 to 6 hours per pesticide spray. Nearly 10 and $17 \%$ of the farmers had spent $<2$ hours and $>6$ hours per pesticide spray (Fig. 3). The majority $(83.2 \%)$ of the farmers reentered potato field at an interval of 5-17 days (Fig. 4). A slightly different result was reported by Shrestha et al. (2010) in Dhading district who found that farmers $(76.6 \%)$ reentered crop field within 0-4 days of pesticide spray. An early entry in pesticides sprayed field results several health problems such as cancer, skin irritation, breathing, and eye problems due to pesticidal exposure. All potato farmers had applied pesticides $>2$ times/season. Ninety-three percent of the farmers had sprayed pesticides 2 to 6 times/season. Nearly $7 \%$ farmers had applied pesticides $>10$ times/season (Fig. 5). A similar result was observed in Chitwan district. Around 58\% of Chitwan's farmers had sprayed pesticides $>4$ times/season whereas 38\% farmers applied pesticides 1-3 times/season (Rijal et al., 2018). The study conducted by Khanal and Singh (2016) also showed an increasing trend of unrestricted use of pesticides by vegetable farmers in Chitwan district. Confusion among farmers to identify the specific cause of crop damage either due to biotic stress (insects, plant diseases and weeds) or abiotic stress particularly drought resulted false perception among farmers that increasing pesticide dose improve crop production. Integrated pesticide management strategies with minimal chemical pesticide dose along with growth stage-based irrigation would be a better fit for low input farming conditions (Katuwal et al., 2018).

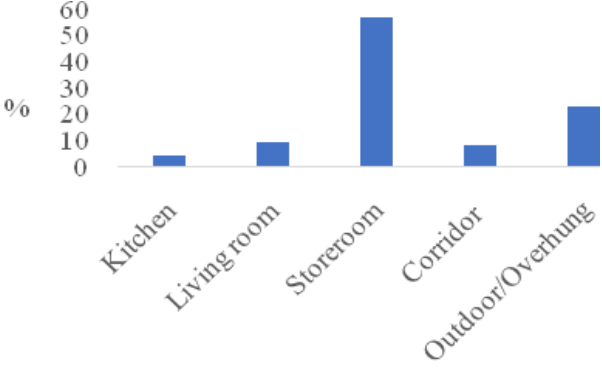

Pesticide storage places

Fig. 2. Pesticides storage places in Panchkhal and Banepa, Kavrepalanchowk

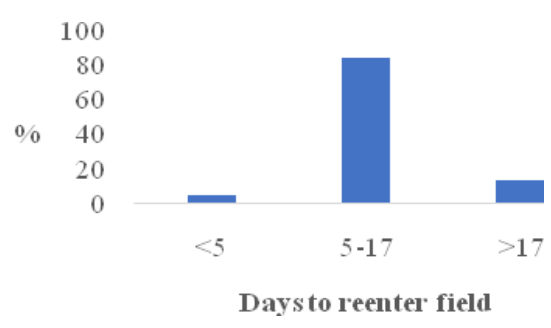

Fig. 4. Days to reenter in potato field in Panchkhal and Banepa, Kavrepalanchowk

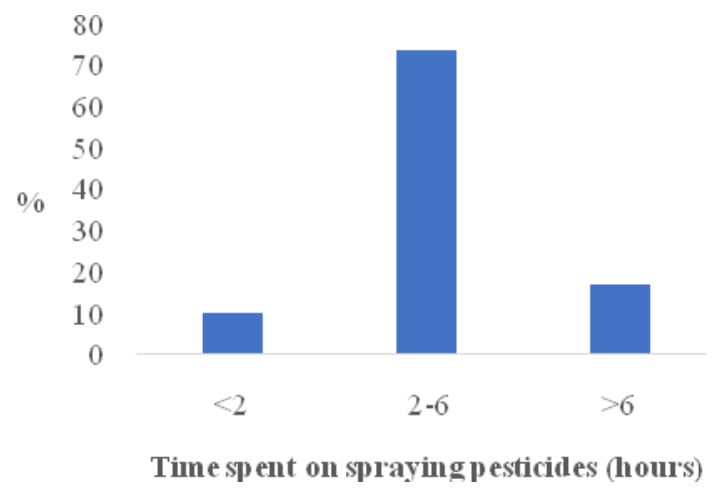

Fig. 3. Time spent on spraying pesticides in potato field in Panchkhal and Banepa, Kavrepalanchowk

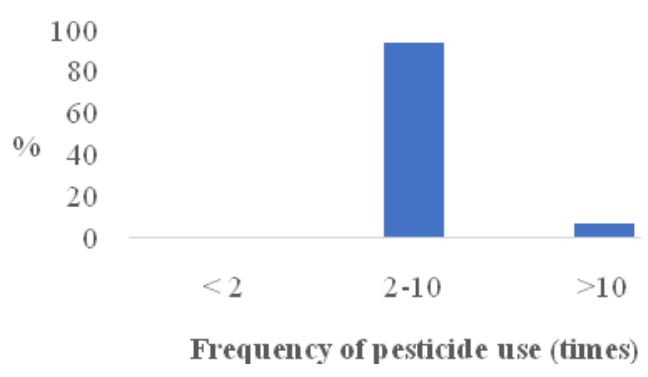

Fig. 5. Frequency of pesticide used/season in potato field in Panchkhal and Banepa, 
Journal of Agriculture and Natural Resources (2020) 3(1): 77-87

ISSN: 2661-6270 (Print), ISSN: 2661-6289 (Online)

DOI: https://doi.org/10.3126/janr.v3i1.27093

\section{Knowledge about pesticides handling practices}

Knowledge about pesticide handling practices among potato growers in Kavrepalanchok is shown in Table 3. The majority $(71.3 \%)$ of the farmers did not read the icon of pesticide labels present on the containers. Low level of education, lack of awareness and use of international language probably reasoned carelessness among the potato farmers. Pesticides labels provide information about hazardous levels, waiting period, application procedures, and precautions. Khanal and Singh (2016) reported that illiterate farmers have difficulty in understanding the instructions and follow safety measures during pesticide application. Awareness and training programs about crop farming and pesticide handling strategies could help farmers to reduce the misuse of inputs and eventually to enhance crop production (Sapkota and Sapkota, 2019). In the study area, 95\% of the farmers had received suggestions from agrovets. Previous studies also demonstrated the role of agrovets in information dissemination. For example, Rijal et al. (2018) in Chitwan district reported that a major portion of the farmers (55\%) entirely rely on agrovets for technical help. This implies that the Nepalese government is almost passive in disseminating information about pesticide to farmers. Our result indicated that a small portion of potato growers were Integrated Pest Management (IPM) trained (12.9\%) and practitioners (24.8\%). Similarly, Shrestha et al. (2010) and Atreya (2005) also reported that a very low number of Nepalese farmers have heard about IPM techniques. Provision of farmer training and extension services could solve pesticide problems along with enhanced farm production (Mahat et al., 2019). IPM techniques emphasize the physical and biological control of pests along with no or minimal use of chemical pesticides. (Konradsen et al., 2003). Training also contributes to higher potato production as it provides the farmers with information about safe handling, storage, application, and disposal of pesticides.

Furthermore, Shrestha and Subedi (2019) reported that the application of good agricultural practices enhances crop production without hampering the environment and climate.

Table 3. Knowledge on pesticide handling practices in Panchkhal and Banepa, Kavrepalanchowk $(\mathbf{N}=\mathbf{1 0 1})$.

\begin{tabular}{lcc}
\hline Parameters & Frequency & Percent \\
\hline Pesticide label readers & 72 & 71.3 \\
No & 29 & 28.7 \\
Yes & & \\
Suggestions received from & 4 & 4 \\
Super zone & 96 & 95 \\
Agrovets & 1 & 1 \\
Radio/Pamphlet & & \\
IPM training participants & 88 & 87.1 \\
No & 13 & 12.9 \\
Yes & & \\
IPM practitioners & 76 & 75.2 \\
No, I have no idea & 25 & 24.8 \\
Yes & &
\end{tabular}

Source: Field Survey, 2018

\section{Status of pesticide use}

Around $44 \%$ potato farmers reported the problem of new pests and diseases. Similarly, 9\% respondents felt increment in frequent pests and disease. However, 28\% respondents reported declining trend of regular potato pests and diseases (Fig. 6). This implies that major portion 
Journal of Agriculture and Natural Resources (2020) 3(1): 77-87

ISSN: 2661-6270 (Print), ISSN: 2661-6289 (Online)

DOI: https://doi.org/10.3126/janr.v3i1.27093

of farmers do not keep accurate records about crop pest incidence, pest's trend and pesticide application.

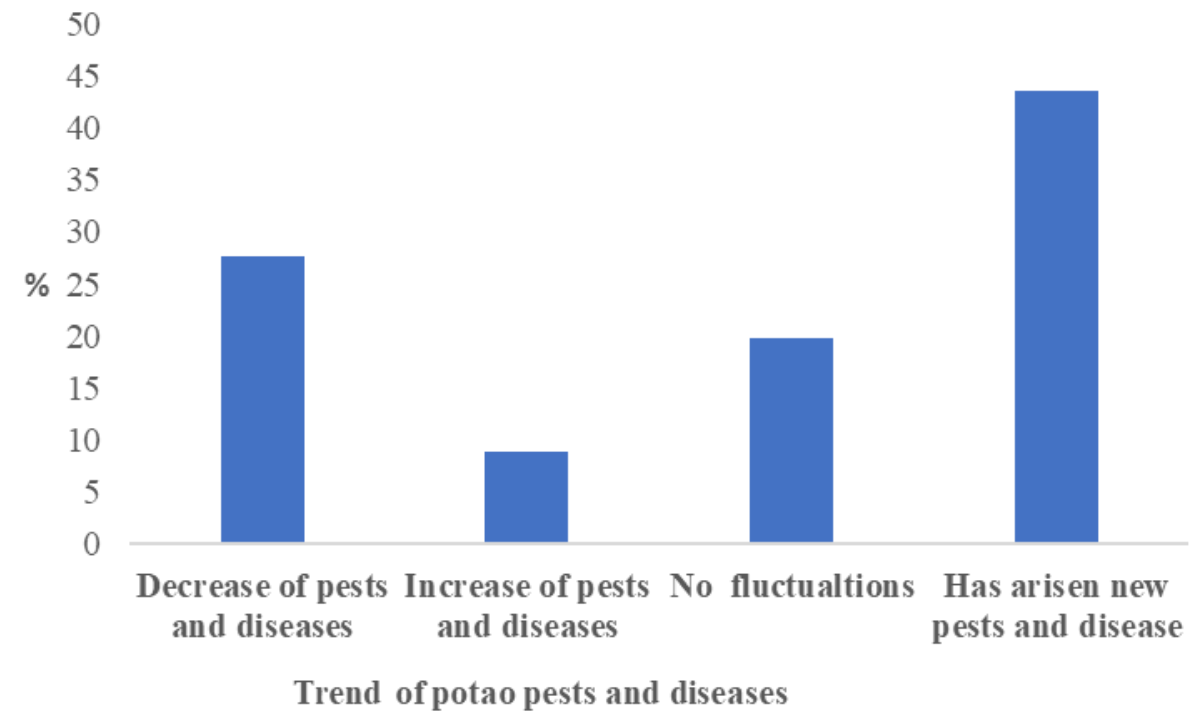

Fig. 6. Trend of potato pests and diseases in Pachkhal and Banepa, Kavrepalanchowk

The average fungicide and insecticide dose used by the potato farmers in the study area was 1.690 caps/tank. Similarly, the average weedicide dose used by the potato farmers was 2.054 caps/tank. The mean number of farmers applying more than one pesticide in a single day was 0.940 .

Table 4. Status of pesticide used in Panchkhal and Banepa, Kavrepalanchowk $(\mathrm{N}=101)$.

\begin{tabular}{llll}
\hline Particulars & Mean & SD & SE \\
\hline Fungicide and insecticide dose (caps/tank) & 1.690 & 0.579 & 0.058 \\
Weedicide applied dose (caps/tank) & 2.054 & 0.740 & 0.122 \\
More than one pesticide users in a single day (numbers) & 0.940 & 0580 & 0.057 \\
\hline Source
\end{tabular}

Source: Field Survey, 2018,1 tank = 16 liters

In the study area, pesticides have been used for a long time. Nearly $75 \%$ of the respondents started to use pesticides since a decade ago (Fig. 7).

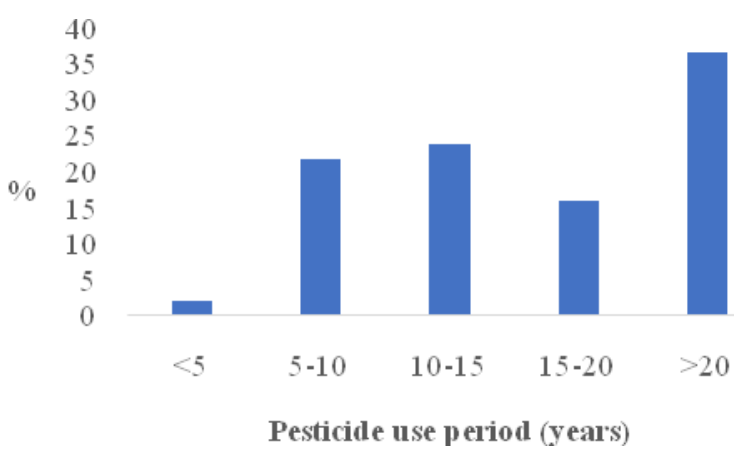

Fig. 7. Pesticide use period in Potato field in Panchkhal and Banepa, Kavrepalanchok 
Journal of Agriculture and Natural Resources (2020) 3(1): 77-87

ISSN: 2661-6270 (Print), ISSN: 2661-6289 (Online)

DOI: https://doi.org/10.3126/janr.v3i1.27093

\section{Status of Personal Protection}

The result indicated that no farmers used complete personal protective equipment (PPE) during pesticide application. The majority of the farmers used a face mask (70.3), rubber boots (54.5) and long sleeves clothes (69.1\%) during pesticide application. Notably, the proportion of the farmers wearing gloves (31.7), google (11.9), hat (37.6), and apron (35.6\%) were very less (Fig. 8). The probable reason could be a lack of awareness, high cost of personal protective apparel, carelessness and feeling of discomfort. A similar result was reported in Chitwan (Rijal et al., 2018) that majority of the farmers wore facemask along with gloves and long-sleeved clothes during pesticide spray. The result was further supported by Koirala et al. (2010) who reported that $70 \%$ of Nepalese farmers use PPE. In contrast, a study in Kavrepalanchok (Atreya et al., 2008) found that only $10 \%$ farmers wear face masks during pesticide application. A total of $85 \%$ farmers have had the whole body shower after pesticide spraying, whereas $15 \%$ farmers only washed their feet but had not taken (Fig. 9). Khanal and Singh (2016) also reported that the majority (72\%) of the commercial vegetable farmers in Chitwan district have had whole body shower after pesticide spray but $14 \%$ farmers washed their hands and feet but had not taken a shower. Furthermore, Koirala et al. (200) mentioned that nearly $52 \%$ farmers had taken whole body shower after pesticide application. A good proportion of farmers $(94.1 \%)$ washed personal protective equipment after pesticide spray (Fig. 9). Our result indicated that the majority $(65.3 \%)$ of the potato farmers in Kavrepalanchowk threw pesticide containers inappropriately in an environment (Fig. 10). This may be due to either carelessness or low education of the farmers. A previous study in Chitwan (Khanal and Singh, 2016) also reported that $74 \%$ of the commercial vegetable farmers had thrown pesticide containers in a nearby water source. A very similar finding was observed by Shrestha et al. (2010) among vegetable growers in the Dhading district. Farmers should properly dispose pesticide containers in order to minimize risks to humans and the environment.

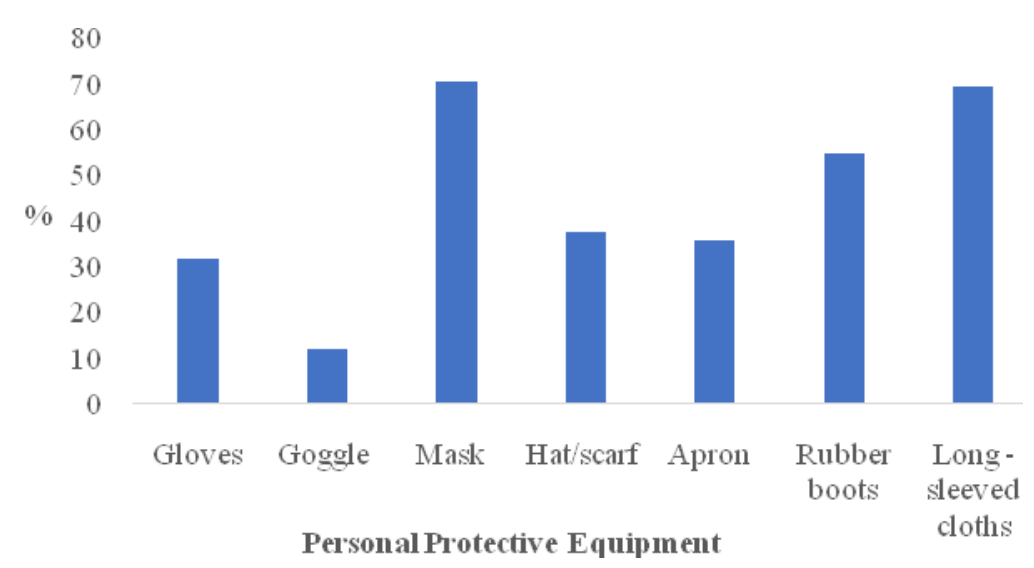

Fig. 8. Personal protective equipment used by potato growers in Panchkhal and Banepa, Kavrepalanchok 
Journal of Agriculture and Natural Resources (2020) 3(1): 77-87

ISSN: 2661-6270 (Print), ISSN: 2661-6289 (Online)

DOI: https://doi.org/10.3126/janr.v3i1.27093

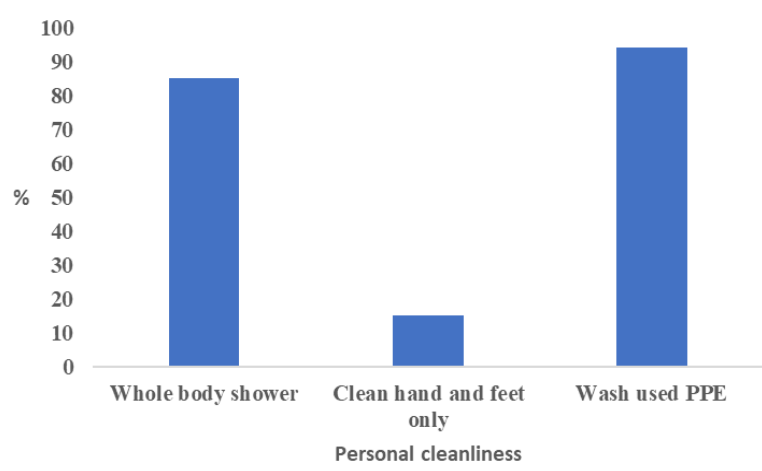

Fig. 9. Personal cleanliness methods adopted by potato growers in Panchkhal and Banepa, Kavrepalanchok

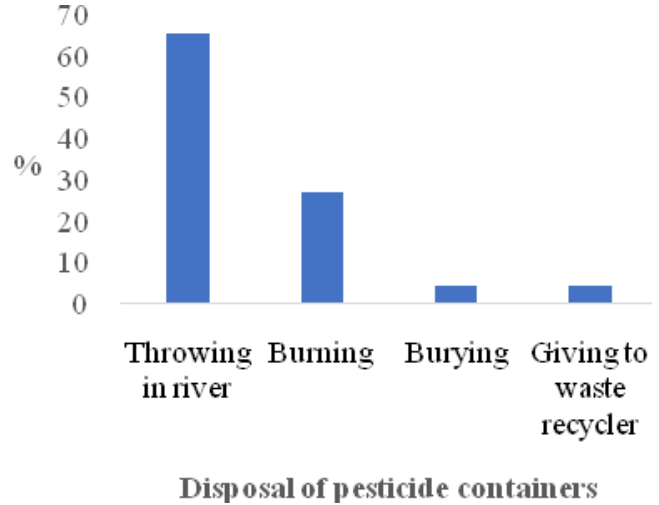

Fig. 10. Disposal of pesticide containers in Panchkhal and Banepa, Kavrepalanchok

\section{CONCLUSION}

In summary, farmers' age, education, training (IPM and pesticide) and use of personal protective equipment are the primary factors in safe pesticide handling practices in Kavrepalanchok. Inappropriate handling and application of pesticides could increase health and environmental risks along with increment in crop production cost. In Kavrepalanchowk, farmers are using pesticides haphazardly, ignoring pesticide labels, PPE, and its impacts on non-target pests and the environment as well. The implications of Nepalese agricultural extension and stakeholders are very low in providing pesticide information and IPM training. Concerned bodies should pay attention to provide farmers training on pesticide handling practices and Integrated Pest Management. The awareness should be disseminated on pesticide misuse and the importance of personal protective equipment. Furthermore, pesticide analysis facilities should be established in different parts of Nepal.

\section{ACKNOWLEDGEMENTS}

The authors would like to thank Professor Dr. Kalyani Mishra Tripathi and Potato Super zone Kavrepalanchok, Kavrepalanchok for their technical support during the research period.

\section{AUTHOR CONTRIBUTIONS}

Conceptualization, K.R.S. (Kashi Ram Sapkota) and S.S. (Sundar Sapkota); methodology, K.R.S. (Kashi Ram Sapkota); data collection, K.R.S. (Kashi Ram Sapkota); data analysis, K.R.S. (Kashi Ram Sapkota) and S.S. (Sundar Sapkota); original draft, K.R.S. (Kashi Ram Sapkota); S.S. (Sundar Sapkota); and S.S. (Sanjib Sapkota); Writing- review and editing, S.S. (Sundar Sapkota); S.S. (Sanjib Sapkota); and K.K (Krishna Katuwal).

\section{CONFLICT OF INTEREST}

Authors declare no conflict of interest. 
Journal of Agriculture and Natural Resources (2020) 3(1): 77-87

ISSN: 2661-6270 (Print), ISSN: 2661-6289 (Online)

DOI: https://doi.org/10.3126/janr.v3i1.27093

\section{REFERENCES}

Atreya, K. (2005). Health costs of pesticide use in a vegetable growing area in central midhills, Nepal. Himalayan Journal of Sciences, 3, 81-83.

Atreya, K. (2008). Health costs from short-term exposure to pesticides in Nepal. Social Science and Medicine, 67(4), 511-519.

Dhital, S., Rupakheti, D., Tripathee, L., \& Sigdel, S. R. (2015). A review on status of pesticides use in Nepal. Research Journal of Agriculture and Forestry Sciences, 3, 26-29.

Giri, Y. P., Maharjan, R., Sporleder, M., \& Kroschel, J. (2009). Pesticide use practices and awareness among potato growers in Nepal. 15th Triennial ISTRC, 2-4.

Kafle, B. K., Pokhrel, B., Shrestha, S., Raut, R., \& Dahal, B. M. (2015). Determination of Pesticide Residues in Water and Soil Samples from Ansikhola Watershed, Kavre, Nepal. International Journal of Geology, Earth \& Environmental Sciences, 5, 119127.

Katuwal, K. B., Angadi, S. V., Singh, S., Cho, Y., Begna, S., \& Umesh, M. R. (2018). Growth-Stage-Based Irrigation Management on Biomass, Yield, and Yield Attributes of Spring Canola in the Southern Great Plains. Crop Science, 58, 2623-2632.

Khanal, G., \& Singh, A. (2016). Patterns of pesticide use and associated factors among the commercial farmers of Chitwan, Nepal. Environmental Health Insights, 10, 1-7.

Koirala, P., Tamrakar, A. S., Bhattarai, B. P., Yadav, B. K., Humagain, S., \& GC, Y. D. (2010). Use and handling practice of pesticides in vegetables: A case study on some selected districts of Nepal. Journal of Food Science and Technology Nepal, 6, 105109.

Konradsen, F., van der Hoek, W., Cole, D. C., Hutchinson, G., Daisley, H., Singh, S., \& Eddleston, M. (2003). Reducing acute poisoning in developing countries-options for restricting the availability of pesticides. Toxicology, 192, 249-261.

Mahat, S., Sapkota, S., Sapkota, S., \& Katuwal, K. (2019). Factors Affecting Ginger Production in Surkhet District, Nepal. International Journal of Applied Sciences and Biotechnology, 7(2), 269-273.

Pimentel, D. (2005). Environmental and economic costs of the application of pesticides primarily in the United States. Environment Development and Sustainability, 7, 229252.

Rijal, J., Regmi, R., Ghimire, R., Puri, K., Gyawaly, S., \& Poudel, S. (2018). Farmers' knowledge on pesticide safety and pest management practices: A case study of vegetable growers in Chitwan, Nepal. Agriculture, 8, 16-27.

Sapkota, S., \& Sapkota, S. (2019). Benefit Cost Analysis of Different Rice Varieties in Kapilvastu District, Nepal. International Journal of Applied Sciences and Biotechnology, 7(2), 222-226.

Sharma, D. R., Thapa, R. B., Manandhar, H. K., Shrestha, S. M., \& Pradhan, S. B. (2012). Use of pesticides in Nepal and impacts on human health and environment. Journal of Agriculture and Environment, 13, 67-74.

Shrestha, P., Koirala, P., \& Tamrakar, A. S. (2010). Knowledge, practice and use of pesticides among commercial vegetable growers of Dhading district, Nepal. Journal of Agriculture and Environment, 11, 95-100.

Shrestha, J., \& Subedi, S. (2019). Improving crop productivity through sustainable intensification. South Asian Research Journal of Agriculture and Fisheries, 1, 8-11. 
Journal of Agriculture and Natural Resources (2020) 3(1): 77-87

ISSN: 2661-6270 (Print), ISSN: 2661-6289 (Online)

DOI: https://doi.org/10.3126/janr.v3i1.27093

SPSS Inc. Released 2009. PASW Statistics for Windows, Version 18.0. Chicago: SPSS Inc.

Yassin, M. M., Mourad, T. A., \& Safi, J. M. (2002). Knowledge, attitude, practice, and toxicity symptoms associated with pesticide use among farm workers in the Gaza Strip. Occupational and Environmental Medicine, 59, 387-393. 